\title{
The relationship between asthma and suicidal behaviours: a systematic literature review
}

\author{
Emma Barker, Kairi Kõlves and Diego De Leo
}

Affiliation: Australian Institute for Suicide Research and Prevention, National Centre of Excellence in Suicide Prevention, World Health Organization Collaborating Centre for Research and Training in Suicide Prevention, Griffith University, Brisbane, Australia.

Correspondence: Kairi Kõlves, Australian Institute for Suicide Research and Prevention, National Centre of Excellence in Suicide Prevention, World Health Organization Collaborating Centre for Research and Training in Suicide Prevention, Griffith University, Level 1, Building M24 Psychology, 176 Messines Ridge Road, Mt Gravatt Campus, Griffith University QLD 4122, Australia. E-mail: k.kolvesđggriffith.edu.au

ABSTRACT Asthma is a highly prevalent chronic condition worldwide, and is particularly common in younger people compared to other chronic conditions. Asthma can result in a number of symptoms that are detrimental to the quality of life of sufferers. The aim of the present systematic literature review was to analyse the existing literature on the relationship between asthma and fatal and nonfatal suicidal behaviours.

Articles were retrieved from Scopus, PubMed, ProQuest and Web of Knowledge. We searched for the terms (suicid* OR self-harm) AND (asthma* OR "bronchial hyperreactivity") published in Englishlanguage peer-reviewed journals between 1990 and December 2014. Original research papers providing empirical evidence about the potential link between asthma and suicidal behaviours were included.

The initial search identified 746 articles. Specific limiting criteria reduced the number of articles to the 19 articles that were finally included in the systematic review.

The review found a potential link between asthma and suicide mortality, ideation and attempts across the age groups. Limitations of the review include the restriction to English-language papers published within the chosen time period, the limited number of papers involving suicide mortality, and the fact that the majority of papers originated from the USA.

@ERSpublications

Systematic literature review suggests potential link between asthma and suicide mortality, ideation and attempts http://ow.ly/Jowfs

Conflict of interest: None declared.

Support statement: The literature review was supported by the Australian Commonwealth Government Department of Health. Funding information for this article has been deposited at FundRef.

Copyright OERS 2015 


\section{Introduction}

The World Health Organization (WHO) estimates that approximately 235 million people worldwide suffer from asthma, this being the most common chronic disease suffered by children [1]. The WHO International Statistical Classification of Diseases and Related Health Problems 10th revision asthma ( J45) includes allergic asthma, nonallergic asthma, mixed asthma, and asthma, unspecified [2].

The symptoms of asthma are usually well managed with the correct use of medications; however, self-management of asthma can be complicated [3]. Certain factors may potentially exacerbate symptoms in sufferers, including smoking behaviour, stress, particular environment triggers (mould, pollen, dust mites and pet hair), exercise and changes in the weather [4]. These symptoms may have a considerable detrimental effect on the quality of life of those suffering from severe and even mild cases of asthma [5].

A link between asthma morbidity, risk-taking behaviour and depression has been presented in previous research, although the reasons and direction of this association are not clear [6]. Four pathways leading to the association have been suggested: 1) particular symptoms of asthma cause distress leading to psychological problems [6]; 2) depression may lead to increased asthma symptoms through risk-taking behaviour (smoking, drinking, nonadherence to medication and poor illness control in general) [6]; 3) depression and psychological stress may be associated with immune system alteration, increased airway inflammation and the initial onset of asthma symptoms in children [7]; and 4) that there may be a common genetic link leading to susceptibility to asthma, atopy and mood disorders [8].

Another potential cause of depression in asthma sufferers is the use of particular medications, including corticosteroids, which, while reducing the symptoms of asthma, have also been linked to mood disturbances similar to the symptoms of major depression [9]. In 2008, the US Food and Drug Administration introduced new warnings about the potential adverse psychiatric symptoms of leukotriene-modifying medications, used in the treatment of asthma. However, as a recent review has shown, research in this area to date has produced very mixed findings [10] and the full extent of the relationship between asthma medications and psychiatric symptoms is yet to be completely understood [10, 11].

As well as being linked to poor physical and mental health, asthma has been associated with suicidal behaviour. In a review of six observational studies, IEsSA et al. [12] found an association between asthma and suicide ideation, attempts and mortality in adults and suicide ideation and mortality in children. The aim of the current review is to present a more comprehensive systematic review of the literature about the relationship between asthma and suicidal behaviour.

\section{Method}

The current review was conducted in accordance with the Preferred Reporting Items For Systematic Reviews And Meta-analyses (PRISMA) statement (table 1) [13].

\section{Search strategy}

A systematic search of Scopus, PubMed, ProQuest and Web of Knowledge was conducted for English-language articles published from January 1990 to December 2014. The search terms used were (suicid* OR self-harm) AND (asthma* OR "bronchial hyperreactivity").

\section{Inclusion criteria}

The initial search retrieved 746 articles before the removal of duplicates and 534 articles after the removal of duplicates. These were limited to 51 potentially relevant papers after perusal of the titles and abstracts to review their relevance to the link between asthma and suicidal behaviours (suicide, suicide attempts and self-harm and suicidal ideation). After reading the full text of these 51 papers, 19 papers presenting original research empirically analysing the potential link between asthma and suicidal behaviour were selected for inclusion in the body of the review. Figure 1 shows a summary of the selection process for papers.

In this article, suicidal behaviour refers to a range of phenomena that include suicide ideation, planning for suicide, self-harming, attempting suicide and suicide. The latter is also defined interchangeably as "fatal suicidal behaviour", while all other phenomena are considered to be "nonfatal suicidal behaviour" [14].

\section{Data extraction}

The following information was extracted for all studies included: author(s) and year of publication; sample size, country and time of the study; study design; measures (asthma and suicidal behaviour); main findings; and quality scores. With regards to the findings, risk ratios, odds ratios (including adjusted odds ratios) and differences in prevalence measured using statistical tests were examined. 
TABLE 1 Checklist of preferred reporting items for systematic reviews and meta-analyses (PRISMA)

Title

Title

Abstract

Structured summary

\section{Introduction}

Rationale

Objectives

Protocol and registration

Eligibility criteria

Information sources

Search

\section{Results}

Study selection

Data collection process

Data items

Risk of bias in individual studies

\section{Discussion}

Summary measures

Synthesis of results
Identify the report as a systematic review, meta-analysis or both

Provide a structured summary including, as applicable: background; objectives; data sources; study eligibility criteria, participants and interventions; study appraisal and synthesis methods; results; limitations; conclusions and implications of key findings; and systematic review registration number

Describe the rationale for the review in the context of what is already known

Provide an explicit statement of questions being addressed with reference to PICOS

Indicate if a review protocol exists, if and where it can be accessed (e.g. web address), and, if available, provide registration information including registration number

Specify study characteristics (e.g. PICOS and length of follow-up) and report characteristics (e.g. years considered, language and publication status) used as criteria for eligibility, giving rationale

Describe all information sources (e.g. databases with dates of coverage and contact with study authors to identify additional studies) in the search and date last searched

Present full electronic search strategy for at least one database, including any limits used, such that it could be repeated

State the process for selecting studies (i.e. screening and eligibility) included in systematic review, and, if applicable, included in the meta-analysis

Describe method of data extraction from reports le.g. piloted forms, independently and in duplicate) and any processes for obtaining and confirming data from investigators

List and define all variables for which data were sought (e.g. PICOS and funding sources) and any assumptions and simplifications made

Describe methods used for assessing risk of bias of individual studies (including specification of whether this was performed at the study or outcome level), and how this information is to be used in any data synthesis

State the principal summary measures (e.g. risk ratio and difference in means) Describe the methods of handling data and combining results of studies, if done, including measures of consistency (e.g. $\left.\mathrm{I}^{2}\right)$ for each meta-analysis (1) (1) (1) 05 (1)

PICOS: participants, interventions, comparisons, outcomes and study design; N/A: not applicable. Information from [13].

\section{Quality scores}

The 19 studies included in the review were each given a quality score (adapted from PompiL et al. [15]) by two of the authors (E. Barker and K. Kõlves). This method allocated each paper a score ranging from 0 to 6 based on the representativeness of the sample, presence of a control/comparison group, number of participants with the condition (asthma), being longitudinal (having a follow-up) and data presentation. More information regarding the determination of these scores is presented in table 2.

\section{Results}

Table 2 presents a summary of the 19 studies reviewed which involved asthma and suicidal behaviour and included risk ratios or odds ratios.

\section{Asthma and suicide mortality}

Five out of the 19 studies in the current review analysed the association between asthma and suicide mortality. The papers originated from different locations, namely the UK $(n=2)$, Taiwan, Canada and Sweden. Three of the papers used a cohort study design, while the remaining two papers used a nested case-control study design.

Kuo et al. [23] used a cohort of 162766 high-school students aged between 11 and 16 years in Taiwan to analyse the relationship between suicide mortality and asthma. The authors compared children with current asthma, previous asthma and no asthma, finding significant differences in the percentages of 
FIGURE 1 Selection process followed when deciding which studies to exclude/include.

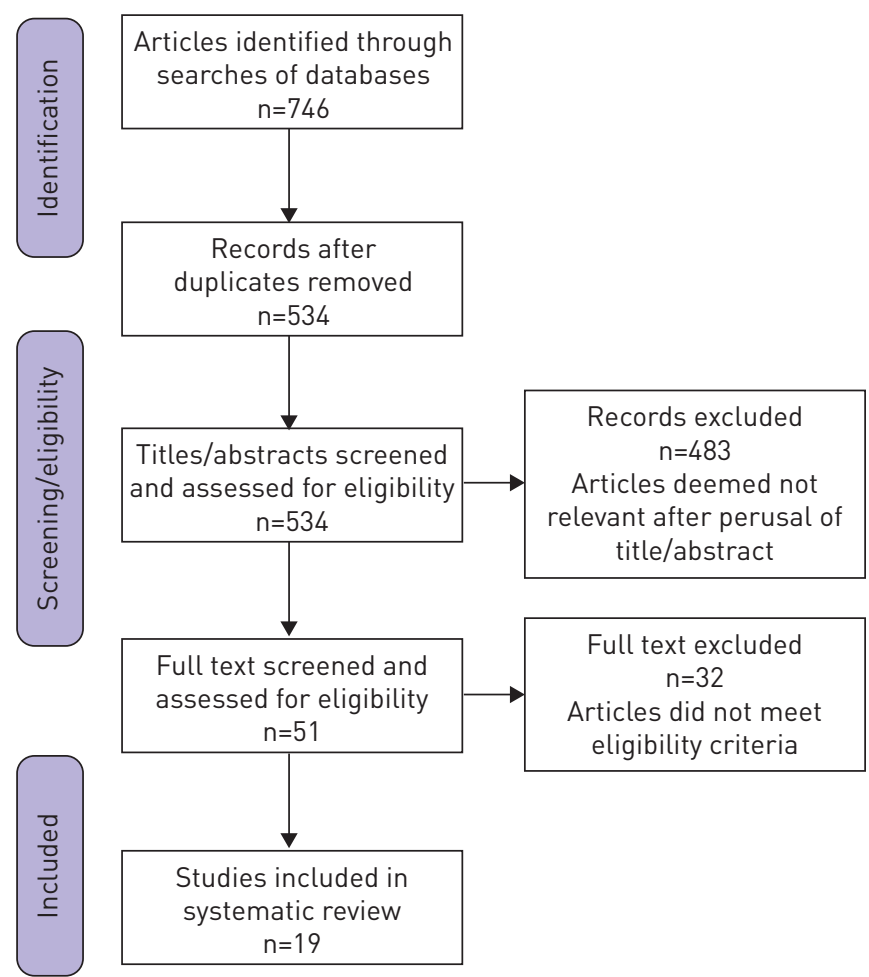

children dying by suicide in each of the groups $(11 \%$ in the current-asthma group, $8.5 \%$ in the previous-asthma group and $4.3 \%$ in the no-asthma group). When other factors including sex, age, personal and family cigarette smoking behaviour and allergic rhinitis were adjusted for, the current-asthma group still had a significantly higher risk of suicide than the group with no asthma, but the differences between the current- and previous-asthma groups were no longer significant. The authors found that particular symptoms, including wheezing while exercising, coughing at night and severe wheezing were associated with suicide risk, and that the risk increased when a greater number of symptoms were present.

Using a national cohort of 7140589 Swedish residents, CRUMP et al. [33] found that asthma was more prevalent among women who died by suicide when compared to the general female population. Further analysis revealed that asthma (and a number of other somatic illnesses) was a significant independent risk factor for suicide in both men and women.

In the UK, Singhal et al. [34] used a retrospective cohort design linking the English Hospital Episode Statistics database with mortality data from 1999 to 2011 to analyse the risk of suicide mortality in people with various psychiatric and physical disorders. 2500814 individuals in the cohort suffered from asthma. This UK study indicated that individuals suffering from asthma were significantly more likely to die by suicide than the comparison group.

Also in the UK, WeBв et al. [29] used a nested case-control design and data from family medical practices recorded in the General Practice Research Database between 2001 and 2008 to test the association between a number of conditions (including asthma) and suicide mortality. WeBB et al. [29] matched 873 adult suicide cases to 17460 living controls by age and sex. Contrary to the results of the cohort studies, including the UK study by SINGHAL et al. [34], this study did not find any increased risk of suicide associated with asthma, or any of the illnesses in the study. However, there was a high percentage of asthma patients reporting depression (64.7\%).

In another nested case-control study, BolTon et al. [32] looked at the association between death by suicide and a number of physical disorders, including asthma. Between 1996 and 2009, 2100 individuals who died by suicide were matched to 6300 controls from the Canadian general population. Multivariate analysis indicated that women with asthma were more likely to die by suicide than women who did not have asthma. No significant increased risk was identified in males with asthma in the adjusted model.

\section{Asthma and suicidal ideation/attempts}

16 papers in the current review included an analysis of nonfatal suicidal behaviour in individuals suffering from asthma. The majority of these studies $(n=10)$ used cross-sectional study designs, followed by cohort 
TABLE 2 Studies of asthma and suicidal behaviour (in chronological order)

\begin{tabular}{|c|c|c|c|c|c|c|}
\hline Authors & $\begin{array}{l}\text { Population, participants } \\
\text { and time }\end{array}$ & Study design & $\begin{array}{l}\text { Measures of } \\
\text { suicidal behaviour }\end{array}$ & Measures of asthma & Main findings & Quality score" \\
\hline Druss and Pincus [16] & $\begin{array}{l}\text { NHANES study of } 7589 \text { individuals } \\
\text { aged } \\
\text { 17-39 years from } 26 \text { states } \\
\text { in USA between } 1988 \\
\text { and } 1994\end{array}$ & Cross-sectional & $\begin{array}{l}\text { Suicidal ideation and } \\
\text { attempts }\end{array}$ & Self-reported asthma & $\begin{array}{l}\text { Asthma, chronic bronchitis and cancer showed a } \\
\text { two-thirds increase in the presence of suicidal } \\
\text { ideation. Around } 1 / 5 \text { of respondents with asthma, } \\
\text { bronchitis, or cancer reported a past suicide } \\
\text { attempt, compared to } 1 / 18 \text { in the general } \\
\text { population. } \\
\text { After adjusting for psychiatric and demographic } \\
\text { factors, people with asthma were still } \\
\text { significantly more likely to report a suicide } \\
\text { attempt laOR 4.34, p<0.001) and suicide ideation } \\
\text { laOR 1.69, p<0.01). }\end{array}$ & $5(|=1, \|=1| I,|=2| V=0,, V=1)$ \\
\hline Gooowin et al. [17] & $\begin{array}{l}998 \text { consecutive adult primary care } \\
\text { patients aged } \\
18-70 \text { years attending } \\
\text { appointments at the Associates in } \\
\text { Internal Medicine clinic } \\
\text { (Columbia-Presbyterian Medical } \\
\text { Centre, Manhattan, NY, USA) } \\
\text { between October } 1998 \text { and April } \\
1999\end{array}$ & Cross-sectional & Suicidal ideation & $\begin{array}{l}\text { Asthma diagnosis from } \\
\text { primary-care physicians }\end{array}$ & $\begin{array}{l}\text { Asthma was significantly associated with suicidal } \\
\text { ideation (OR 1.9, } 95 \% \mathrm{Cl} 1.03-3.4 \text { ) and with panic } \\
\text { attack after controlling for socio-demographic } \\
\text { factors and mental disorders. Asthma was not } \\
\text { significantly associated with major depression, } \\
\text { generalised anxiety disorder, alcohol, or drug use } \\
\text { disorders. }\end{array}$ & $3(|=0,\|I=1\| I|=1,, \mid V=0, V=1)$ \\
\hline $\begin{array}{l}\text { GoodWIN and } \\
\text { MARUSIC [18] }\end{array}$ & $\begin{array}{l}\text { MECA study of } 1285 \text { youths aged } \\
9-17 \text { years from four sites in USA }\end{array}$ & Cross-sectional & $\begin{array}{l}\text { Suicidal ideation ("In } \\
\text { the past } 6 \text { months } \\
\text { have you thought } \\
\text { about suicide or } \\
\text { killing yourself?") }\end{array}$ & $\begin{array}{l}\text { Parental reports of past } \\
\text { hospitalisation for } \\
\text { asthma }\end{array}$ & $\begin{array}{l}\text { Youths with asthma were significantly more likely to } \\
\text { report suicidal ideation than those without } \\
\text { asthma, even when adjusting for } \\
\text { sociodemographic characteristics and comorbid } \\
\text { mental disorders (aOR } 3.25,95 \% \mathrm{Cl} 1.04-10.1 \text { ). }\end{array}$ & $3(\mid=1, \|=1, I I I=0, I V=0, V=1)$ \\
\hline $\begin{array}{r}\text { Goodwin and } \\
\text { Eaton [19] }\end{array}$ & $\begin{array}{l}\text { Baltimore (MD, USA) follow-up of the } \\
\text { Epidemiologic Catchment Area } \\
\text { Study: } 3481 \text { community } \\
\text { participants aged } \geqslant 18 \text { years in } \\
\text { USA studied in } 1981 \text { (wave 1) and } \\
1982 \text { (wave 2); } 1920 \text { individuals } \\
\text { (74\% of the original sample) } \\
\text { followed-up in 1993-1996 (wave 3) }\end{array}$ & Cohort study & $\begin{array}{l}\text { Suicidal ideation and } \\
\text { attempts } \\
\text { measured at } \\
\text { three time points }\end{array}$ & Self-reported asthma & $\begin{array}{l}\text { Several associations between asthma and suicidality } \\
\text { at different waves were found to be significant. } \\
\text { However, current asthma at wave } 1 \text { of the study } \\
\text { was associated with a significantly increased risk } \\
\text { of suicidal ideation at wave } 2 \text {, after controlling for } \\
\text { sex, age, race, asthma treatment and lifetime } \\
\text { major depression (OR } 2.3,95 \% \mathrm{Cl} 1.03-5.25 \text { ). } \\
\text { Current asthma at wave } 1 \text { was also associated } \\
\text { with significantly increased risk of suicide } \\
\text { attempts at wave } 2 \text { when controlling for the same } \\
\text { variables (OR } 3.54,95 \% \mathrm{Cl} 1.4-8.99) \text {. Analysis at } \\
\text { wave } 3 \text { of the study was not included as the cell } \\
\text { sizes became too small for comparison due to } \\
\text { participant attrition. }\end{array}$ & $5(|=1, \|=1, I| I=1, \mid V=1, V=1)$ \\
\hline Bender [20] & $\begin{array}{l}\text { YRBS study of } 13917 \text { youth in school } \\
\text { grades } 9-12 \text { from } 40 \text { states and } 21 \\
\text { cities in USA in } 2005\end{array}$ & Cross-sectional & $\begin{array}{l}\text { Suicidal ideation and } \\
\text { attempts }\end{array}$ & $\begin{array}{l}\text { Self-reported lifetime } \\
\text { diagnosis of asthma and } \\
\text { asthma symptoms in } \\
\text { past } 12 \text { months }\end{array}$ & $\begin{array}{l}\text { Students with asthma were significantly more likely } \\
\text { to report depressive symptoms, suicidal } \\
\text { thoughts, plans, actions and injuries than their } \\
\text { nonasthmatic peers: } 31 \% \text { reported considering } \\
\text { suicide compared to } 16.2 \%(p<0.001) \text { and } 17.9 \% \\
\text { had made a suicide attempt compared to } 8.5 \% \text { of } \\
\text { the nonasthmatic group }(p<0.001) \text {. }\end{array}$ & $5(|=1, \|=1| I,|=2| V=0,, V=1)$ \\
\hline NomURA et al. [21] & $\begin{array}{l}\text { Regional random sample of } 2694 \\
\text { individuals born between } 1960 \\
\text { and } 1964 \text { (perinatal conditions } \\
\text { measured at delivery); } 1525 \text { were } \\
\text { followed-up in adulthood (27- } \\
33 \text { years in 1992-1994) in } \\
\text { Baltimore (MD, USA) }\end{array}$ & Cohort study & Suicidal ideation & $\begin{array}{l}\text { Self- reported current or } \\
\text { past asthma }\end{array}$ & $\begin{array}{l}\text { Offspring with suicidal ideation had a significantly } \\
\text { increased risk of comorbid asthma when } \\
\text { confounding factors were adjusted for laOR } 2.8, \\
95 \% \mathrm{Cl} 1.4-5.8 \text {. There was no evidence that } \\
\text { perinatal risk factors increased the risk of } \\
\text { comorbid suicidal ideation and asthma. }\end{array}$ & $5(|=1,\|=1\|,| \|=1, \mid V=1, V=1)$ \\
\hline
\end{tabular}


TABLE 2 Continued

\begin{tabular}{|c|c|c|c|c|c|c|}
\hline Authors & $\begin{array}{l}\text { Population, participants } \\
\text { and time }\end{array}$ & Study design & $\begin{array}{l}\text { Measures of } \\
\text { suicidal behaviour }\end{array}$ & Measures of asthma & Main findings & Quality score ${ }^{\#}$ \\
\hline CLARKE et al. [22] & $\begin{array}{l}\text { NCS-R study of } 5692 \\
\text { English-speaking individuals aged } \\
\geqslant 18 \text { years and living in USA } \\
\text { between February } 2001 \text { and April } \\
2003\end{array}$ & Cross-sectional & $\begin{array}{l}\text { Suicidal ideation and } \\
\text { attempts }\end{array}$ & $\begin{array}{l}\text { Self-reported diagnosed } \\
\text { asthma }\end{array}$ & $\begin{array}{l}\text { A statistically significant association between } \\
\text { asthma and suicidal ideation with attempts (OR } \\
1.98,95 \% \mathrm{Cl} 1.42-2.76 \text { ), but not suicidal ideation } \\
\text { alone (OR } 1.09,95 \% \mathrm{Cl} 0.81-1.45 \text { ) was found. } \\
\text { After controlling for age, sex and race/ethnicity, } \\
\text { the relationship between suicide attempts and } \\
\text { asthma reduced by } 6.1 \% \text { reducing by a further } \\
16 \% \text { when smoking and nicotine dependence was } \\
\text { accounted for. In addition, the association } \\
\text { decreased by } 12.4 \% \text { when depression, panic } \\
\text { disorder and alcohol dependence or abuse were } \\
\text { adjusted for; however, the association remained } \\
\text { significant laOR } 1.53,95 \% \mathrm{Cl} 1.06-2.21 \text {. }\end{array}$ & $5(|=1,\|=1\| I|=2,, \mid V=0, V=1)$ \\
\hline Kuo et al. [23] & $\begin{array}{l}\text { The Study of Asthma and Allergy of } \\
162766 \text { high-school students aged } \\
11-16 \text { years in October } 1995-J u n e \\
1996 \text { and their parents was linked } \\
\text { with the national death } \\
\text { certification system in Taiwan up } \\
\text { to December } 2007\end{array}$ & Cohort study & Suicide mortality & $\begin{array}{l}\text { Self-reported current and } \\
\text { previous asthma } \\
\text { symptoms }\end{array}$ & $\begin{array}{l}\text { When comparing groups with current asthma, } \\
\text { previous asthma and no asthma, the only } \\
\text { significant between-group effect was observed in } \\
\text { suicide deaths: } 11 \text { per } 100000 \text { person-years, } 8.5 \\
\text { per } 100000 \text { person-years and } 4.3 \text { per } 100000 \\
\text { person-years, respectively (p<0.001). There were } \\
\text { no significant differences in natural deaths } \\
\text { between the three groups. After adjusting for sex, } \\
\text { age, personal and family cigarette smoking and } \\
\text { allergic rhinitis, the current-asthma group had a } \\
\text { significantly higher likelihood of suicide mortality } \\
\text { than the no-asthma group (HR } 2.26,95 \% \mathrm{Cl} 1.43- \\
\text { 3.43), but not the previous-asthma group. } \\
\text { Particular symptoms of asthma lexercise } \\
\text { wheezing, night cough and severe wheezing) } \\
\text { were significantly associated with suicide risk } \\
\text { after adjusting for covariates. Having a greater } \\
\text { number of symptoms increased risk of suicide. }\end{array}$ & $6(|=1,\|=1\| I|=2,, \mid V=1, V=1)$ \\
\hline BAE et al. [24] & $\begin{array}{l}\text { The } 2008 \text { KYRBWS study of } 75238 \\
\text { Korean youths attending middle or } \\
\text { high school }\end{array}$ & Cross-sectional & $\begin{array}{l}\text { Self-reported } \\
\text { suicidal ideation } \\
\text { and attempts }\end{array}$ & $\begin{array}{l}\text { Self-reported diagnosis and } \\
\text { treatment of asthma }\end{array}$ & $\begin{array}{l}\text { The results of the study showed higher prevalence } \\
\text { of suicidal ideation and attempts in current and } \\
\text { former asthmatics when compared to their peers } \\
\text { without asthma. These results remained } \\
\text { significant when controlling for confounding } \\
\text { factors for both considering suicide (OR } 1.36 \text {, } \\
95 \% \mathrm{Cl} 1.19-1.55 \text { and OR } 1.40,95 \% \mathrm{Cl} 1.27-1.54, \\
\text { respectively) and attempting suicide } \text { (OR } 1.55, \\
95 \% \mathrm{Cl} 1.25-1.92 \text { and OR } 1.54,95 \% \mathrm{Cl} 1.29-1.84, \\
\text { respectively). aOR also showed a significant } \\
\text { relationship between current or former asthma, } \\
\text { suicidal ideation and current cigarette use and } \\
\text { cigarette use before the age of } 13 \text { years. Suicidal } \\
\text { ideation was an effect modifier of the relationship } \\
\text { between asthma and cigarette use. }\end{array}$ & $5(|=1,\|=1\| I|=2,, \mid V=0, V=1)$ \\
\hline CHAN et al. [25] & $\begin{array}{l}\text { National Survey of Health Promotion } \\
\text { Knowledge, Attitudes, and Practice } \\
\text { of } 3853 \text { elderly adults aged } \\
>65 \text { years in Taiwan in 2002-2003 }\end{array}$ & Cross-sectional & Suicidal ideation & $\begin{array}{l}\text { Self-reported diagnosis of } \\
\text { asthma }\end{array}$ & $\begin{array}{l}\text { Univariate analysis showed significant association } \\
\text { between suicidal ideation and asthma (OR } 2.84, \\
95 \% \mathrm{Cl} 1.76-4.58 \text { ). Asthma did not remain a } \\
\text { significant predictor of suicidal behaviours in a } \\
\text { multivariate logistic regression analysis. }\end{array}$ & $4(|=1, I I=1| I,|=1| V=0,, V=1)$ \\
\hline
\end{tabular}




\section{CHRISTIANSEN and}

3465 children and youths born between 1983 and 1989 who attempted suicide were matched identical age and sex 169300 controls) using Danish national population registers and followed until 2005

Chung and Joung [27]

13958 youths in USA who completed the YRBS and

48814 Korean youths who

completed the Korean Youth

Behavioral Risk Factor Surveillance Survey aged 1218 years in 2007

Gooowin et al. [28] 6584 adults aged 20-39 years who participated in NHANES III between 1988 and 1994 in USA

registered with the GPRD, linked

with national mortality records of

873 adult suicide cases matched

by age and sex with 17460 living

controls between 2001 and 2008

WEBB et al. [30]

Routinely collected UK primary-care records of 2306 self-harm cases and 46120 age- and sex-matched controls from the GPRD between 2001 and 2008

Age at first episode of self-harm

ranged from 17 to 87 years
Hospital records of asthma hospital

Cross-sectiona

attempts

Self-reported diagnosis of asthma

icidal ideation and Self-reported diagnosed attempts asthma

Nested case-control Suicide mortality

Asthma diagnosis from primary-care records

For both male and female patients, treatment for

asthma was a significant risk factor for

attempted suicide (rate ratio $(95 \% \mathrm{Cl}) 1.57$

$(p<0.0001)$, respectively). The risk of suicide was

greatest in the first couple of weeks after contact

with the somatic department. When adjusting for

possible confounding variables (i.e. child's

psychiatric history, parent's psychiatric history,

level of income and education) asthma was not

an independent risk factor for suicide (rate ratio

(95\% Cll for males 1.11 (0.78-1.59) and females $1.02(0.83-1.24))$.

Results indicated that a medical diagnosis of

asthma was a significant risk factor for both
suicidal ideation laOR $1.15,95 \% \mathrm{Cl} 1.06-1.25$ ) and

attempt (aOR 1.44, 95\% Cl 1.28-1.63) in the

Korean youth sample, but not in the USA youth

sample.

Compared to individuals without asthma, current asthma status was associated with higher risk of suicidal ideation (OR 2.07, 95\% $\mathrm{Cl} 1.28-3.34$ ) and suicide attempt (OR $3.83,95 \% \mathrm{Cl} 2.32-6.34$ ). which remained statistically significant lalthough somewhat reduced) after controlling for demographic characteristics, smoking depression, dysthymia mania and allergy Isuicide depression, dysthymia, mania and altergy Isuicide attempt OR 3.26, 95\% C1 1.97-5.39). There was no . significant relationship between former asthma variables were adjusted for.

variables were adjusted for.

Overall, there was no higher suicide risk in those with any of the 11 physical illnesses studied combined (aOR 0.89, 95\% Cl 0.75-1.04). Asthma was not significantly associated with increased suicide mortality before or after controlling for depression (aOR 0.84, 95\% $\mathrm{Cl} 0.66-1.08$ ). $64.7 \%$ of asthma cases had depression, which was the second most frequent comorbidity after back pain.

Nested case-control Self-harm Asthma diagnosis from primary-care records

Overall, patients diagnosed with any of the included physical illnesses had almost 50\% higher risk of self-harm. Separate analysis showed that 9 out of the 11 illnesses had significantly increased risk; however, when controlling for depression, only however, when controlling for depression, only and epilepsy remained significant Haring come increased the risk of self-harm in women but not men when controlling for depression. $6(\mid=1, I I=1, I I I=2, I V=1, V=1$

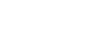

$6(|=1|,|=1|||=2,, \mid V=1, V=1)$

.


TABLE 2 Continued

Authors

Population, participants

Study design

Measures of

Measures of asthma

Main findings

Quality score"

BANDIERA et al. [31] 1550 Puerto Rican youths aged 1116 years and living in the South Bronx (New York, NY, USA), San Juan and Caguas (Puerto Rico) participating in the Boricua Youth Study of antisocial behaviours and other psychiatric disorders (wave 3) in 2000-2004

BoLton et al. [32] 2100 individuals from Manitoba (Canada) who died by suicide between 1996 and 2009 were matched with 6300 general population controls

8641 individuals with suicide attempts were compared to 25923 matched controls

Data were obtained from the

Population Health Research Data Repository at the Manitoba Centre for Health Policy

Ages ranged from those born in 1940 Ages ranged from those born in 1940
and earlier to those born in 1991 and later

CRUMp et al. [33] National cohort of 7140589 Swedish adults aged $\geqslant 18$ years were followed for suicide mortality using the Swedish death registry

Cross-sectional

Self-reported suicidal thoughts and ideation, past suicide attempts and suicidal plans within the past year

\section{Nested case-control Suicide mortality} and suicide attempts

Physici (nician-diagnosed sthma as recorded in registry

Parental reports of asthm
in past year
Physician-diagnosed
asthma as recorded in
the Manitoba health
registry
in outpatient and hospital registries between 2001 and 2008

SinghaL et al. [34] Cohort from nationwide dataset of English Hospital Episode Statistics linked with mortality data from 1999 to 2011

2500814 individuals with asthma were included and ages ranged from children to adults $110-$ $>65$ years)

\section{Cohort study \\ Self-harm and \\ Hospital admissions for} suicide mortality asthma suicide among both men and women
Those with asthma were $\sim 1.7$ times $195 \%$ Cl 1.11 2.64) more likely to experience suicidal ideation or behaviour than those without asthma. This association was significant even when controlling for demographics, socioeconomic status, major depression, conduct disorder, PTSD, cigarette smoking and stressful life events.

In unadjusted models, asthma was significantly associated with increased risk of suicide mortality (OR 1.50, 95\% Cl 1.32-1.71; $p<0.001$ ). In the adjusted model, asthma was no longer significantly associated with suicide risk overall laOR 1.03, 95\% $\mathrm{Cl} 0.88-1.22$ ); however, the risk remained significant in women laOR $1.41,95 \% \mathrm{Cl}$ $1.06-1.86 ; p<0.05)$. Asthma was associated with risk of suicide attempts after adjusting for ADG count, depression, anxiety disorders, substance abuse, schizophrenia, dementia and all other physical disorders laOR 0.84, 0.75-0.93; $p<0.001$ ).

$5(I=1,\|=1\| I=1,, I V=0, V=1)$

$6(|=1|,|=1|||=2,, \mid V=1, V=1)$

ivariate analysis indicated that asthma $(p=0.02)$ was more prevalent among women who died by suicide compared to the rest of the population Further multivariate analysis indicated that a number of somatic disorders, including asthma, were significant independent risk factors for laHR $\sim 1.4-2.1]$.

Asthma was associated with an increased risk of self-harm (rate ratio $1.8,95 \% \mathrm{Cl} 1.8-1.9$ ), the highest risk being in those aged 45-64 years (rate ratio $2.2,95 \% \mathrm{Cl} 2.1-2.2$. Those suffering from asthma were also significantly more likely to die by suicide than those in the reference cohor Irate ratio $1.2 .95 \% \mathrm{Cl} 1.1-1.3 ; \mathrm{p}<0.05$ ).
$6(|=1, I I=1| I I=2,, \mid V=1, V=1)$

$6(|=1| I=1,,|I|=2, \mid I V=1, V=1)$

NHANES: National Health and Nutrition Examination Survey; aOR: adjusted odds ratio; MECA: Methods for the Epidemiology of Child and Adolescent Mental Disorders; YRBS: Youth Risk Behavior Survey; NCS-R: National Comorbidity Survey Replication; HR: hazard ratio; KYRBWS: Korea Youth Risk Behaviour Web-based Survey; GPRD: General Practice Research Database; PTSD: post-traumatic stress disorder; ADG: Johns Hopkins Aggregated Diagnosis Groups; aHR: adjusted hazard ratio. ${ }^{\#}$ : Quality ratings have a maximum score of 6. The following criteria were used to assess quality. I: representativeness of the sample to the general population ( $0=$ not representative, $1=$ representative); II: presence of a control/comparison group ( $0=$ no control/comparison group, $1=$ control/comparison group); III: number of participants with history of the condition lasthma) ( $0=<100$, $1=<500$, $2=>500)$; IV: longitudinal (follow-up) (0=no, 1=yes); V: data presentation ( $0=$ unclear data presentation, (1=clear data presentation) (adapted from PompILI et al. [15]). 
study designs $(n=3)$ and nested case-control study designs $(n=3)$. Studies originated from a relatively wide range of countries/areas including USA $(n=9)$, UK $(n=2)$, USA/Korea $(n=1)$, Korea $(n=1)$, Taiwan $(n=1)$, Denmark $(n=1)$ and Canada $(n=1)$.

Seven of the studies using cross-sectional designs included measures of both suicidal ideation and attempts in people suffering from asthma, while another three studies focused solely on suicidal ideation. The three papers focusing solely on suicidal ideation found significant associations between asthma and suicidal ideation in children [17], adults [18] and elderly adults aged $>65$ years [25]. The majority of studies including both suicidal ideation and attempts found that asthma was associated with increased risk of both ideation and attempts in adults $[16,28]$ and children [20, 24, 31]. Two of the papers reported less conclusive results: the study by CLARKE et al. [22] was the only one to find that asthma was associated with suicidal ideation including attempt(s), but not with suicidal ideation alone. The study performed in both USA and Korea found an association between suicidal ideation and attempts in Korean youth but not American youth [27]. Two cohort studies from USA found that asthma was significantly associated with suicidal ideation in adults [19, 21]. GOodwin and EATON [19] also found that asthma was associated with increased risk of suicide attempts, which remained significant when controlling for sex, age, race, asthma treatment and lifetime major depression. The cohort study from the UK found that asthma was significantly associated with an increased risk of self-harm, particularly in the 45-64 year age group [34]. Significantly increased risk was not found in those suffering from cancer, congenital heart disease, ulcerative colitis, sickle-cell anaemia or Down's syndrome. Three nested case-control designs focused on self-harm [30] and suicide attempts [26, 32]. WEBв et al. [30] included a number of different somatic conditions, finding that after controlling for depression, only asthma, back pain and epilepsy were significant predictors of self-harm. BolTon et al. [32] found that asthma was significantly associated with attempted suicide after controlling for Johns Hopkins Aggregated Diagnosis Groups count, depression, anxiety disorders, substance abuse/dependence, schizophrenia, dementia, other psychosocial disorders and all physical disorders. Conversely, while Christiansen and STEnager [26] found that individuals treated for asthma were at a higher risk of suicide attempt, particularly within the first couple of weeks of contact with the somatic department, this result did not remain significant after controlling for other factors.

\section{Discussion}

Suicidal behaviour has been associated with poor physical health status [35], depression [36] and risk-taking behaviour [37], factors which are all commonly seen in asthma sufferers. It has been hypothesised that the presence of these risk factors in asthma sufferers may interact to result in an increased risk of suicidal behaviour in these individuals. In addition, recent research by DARLINGTON et al. [38] has suggested that there may be a common genetic link between asthma and suicidality. The current review supports the association between asthma and suicidality, with a number of studies finding an increased risk of suicide mortality [23,33] and nonfatal suicidal behaviour [16, 19-22, 27, 30, 31] in asthma sufferers. Only two of the studies failed to find any significant association between asthma and suicidality $[26,29]$. The results of studies including a number of different physical illnesses suggested that asthma may present a higher risk than a number of other somatic conditions [30, 33].

There have been some suggestions that medications used to treat the symptoms of asthma may help to explain the increased risk of suicidal behaviours in asthmatics. However, the research pertaining to the use of asthma medications and suicide risk has returned very mixed findings, with a number of studies failing to find an increased risk in individuals using these medications [39-41]. One study indicated that risk associated with asthma medications may be higher than certain types of medications for other conditions (selective serotonin reuptake inhibitors), but that risk may depend on the type of asthma medication used [42]. The other finding, that increased suicide risk was in association only with the use of theophylline for asthma, but not with another type of asthma medication (long-acting $\beta$-agonists), supported this possibility [43]. While there are currently not enough available studies in this area to analyse suicide risk depending on the particular asthma medication used, this may be a useful topic to explore in the future.

Asthma is a chronic condition which is very prevalent in younger age groups [1]. A number of studies in the current review focused on the risk of suicide and suicidal behaviour in children and adolescents suffering from asthma, and indicated that young individuals who are suffering from asthma may be at an increased risk of suicide mortality [23], ideation [18] and attempts [20, 24, 31]. Studies also explored the potential impact of risk-taking behaviours in this age group, finding that a large percentage of children who experienced suicidal behaviour had engaged in cigarette smoking (40\%), marijuana use (60\%) and binge drinking (37\%) [20]. The findings of $\mathrm{BAE}$ et al. [24] supported this, finding significant interactions between asthma, suicidal ideation and cigarette smoking behaviours in youth. Despite these findings, there is no evidence to suggest that children and adolescents are particularly at-risk compared to other age groups, as asthmatic adults and elderly individuals have also been found to have an increased risk of suicidal behaviour. 
While there is too little information available to determine if there are any clear sex differences, CLARKE et al. [22] did find that risk of suicidality was increased when asthma sufferers were female, depressed, anxious, smokers, abusers of alcohol or nicotine dependent. Wевв et al. [30] found that having two or more comorbid medical conditions increased the risk of self-harm in women, but not in men. Furthermore, after adjusting for mental disorders, BolTon et al. [32] found that asthma remained significantly associated with suicide in women, but not in men. Based on these limited findings, more research exploring the potential for sex differences may be warranted.

\section{Implications}

The findings of the current review lend support to the existence of a link between suicidal behaviour and asthma in adults and children/adolescents. In particular, young people who engage in risky behaviour including smoking and alcohol/drug use appear to be especially susceptible, and it may be prudent for individuals caring for these children to be wary of the potential for suicidal behaviours in this group [20, 24]. Furthermore, it is likely that these risky behaviours result in poor asthma control and medication adherence, suggesting the need to ensure that young individuals are treating their asthma appropriately [6].

It is possible that the severity and timing of asthma symptoms increases the chances of suicidal behaviour, shown by the findings that particular symptoms or a number of different symptoms may present a greater risk [23]. Furthermore, it appears that risk may be highest in the weeks after medical treatment is sought [33]. As a result, it may be important for medical practitioners to be aware of this potential risk while treating individuals with severe asthma symptoms.

The findings of studies regarding asthma medication and suicide risk have produced mixed results and there appears to be little conclusive evidence consistently linking these medications to suicidal behaviour. It may be possible that particular medications are associated with suicide risk while others are not; however, it is clear that more research is needed on this topic before the safety of these medications can be determined.

\section{Limitations}

The limitations and potential for bias of both the current review and the individual studies in the review has been assessed. The current review was restricted to English-language articles published in peer-reviewed journals at the time of the searches. Therefore data published in grey literature (i.e. government reports) or in other languages are not included, which may have resulted in the exclusion of some potentially relevant papers. Only five studies involved suicide mortality. A large number of papers on nonfatal suicidal behaviour originated from the USA, a fact that may limit the generalisability of findings to other countries. Studies used varying methodology to determine whether participants suffered from asthma and/or suicidal behaviour, which may affect the ability to compare results from single contributions. For example, a number of studies relied on self-reported indications of asthma and/or suicidality, and this will inevitably involve some degree of inaccuracy [16, 18, 20-24, 28, 31]. Conversely, studies including only asthma sufferers who had received hospital or other medical treatments might have excluded those individuals who did not seek that specific treatment for their illness $[17,29,30]$. Lastly, the large number of descriptive cross-sectional study designs used in the reviewed studies makes it difficult to determine the direction of causality in the relationship between suicidal behaviour and asthma.

\section{Conclusions}

Asthma is an important chronic condition that has previously been linked to a number of adverse outcomes including depression and risk-taking behaviour. There is currently a body of research suggesting a link between suicidal behaviour and asthma; however, little is known about the direction of this relationship and potential at-risk subgroups. Nevertheless, it appears that asthmatics may be at an increased risk of suicidal behaviour across all ages. The possibility of asthma medications exacerbating suicidal behaviour is still unclear, and more research is needed in this area.

\section{References}

1 World Health Organization. Scope: asthma (2014). www.who.int/respiratory/asthma/scope/en Date last accessed: August 16, 2014.

2 World Health Organization. International statistical classification of diseases and related health problems $10^{\text {th }}$ revision (2010). http://apps.who.int/classifications/icd10/browse/2010/en Date last accessed: August 16, 2014.

3 Main J, Moss-Morris R, Booth R, et al. The use of reliever medication in asthma: the role of negative mood and symptom reports. J Asthma 2003; 40: 357-365.

4 Asthma Australia. Asthma: basic facts (2013). www.asthma.org.au/Portals/0/doc/Brochures/Asthma\%20Australia/ AA-Basic-Facts-0312.pdf Date last accessed: September 5, 2014.

5 Juniper EF. Effect of asthma on quality of life. Can Respir J 1998; 5: Suppl. A, 77A-84A

6 Bender BG. Risk taking, depression, adherence, and symptom control in adolescents and young adults with asthma. Am J Respir Crit Care Med 2006; 173: 953-957. 
Calam R, Gregg L, Simpson A, et al. Behavior problems antecede the development of wheeze in childhood: a birth cohort study. Am J Respir Crit Care Med 2005; 171: 323-327.

8 Wright RJ, Cohen RT, Cohen S. The impact of stress on the development and expression of atopy. Curr Opin Allergy Clin Immunol 2005; 5: 23-29.

9 Patten SB, Neutel CI. Corticosteroid-induced adverse psychiatric effects: incidence, diagnosis and management. Drug Saf 2000; 22: 111-122.

10 Schumock GT, Lee TA, Joo MJ, et al. Association between leukotriene-modifying agents and suicide: what is the evidence? Drug Saf 2011; 34: 533-544.

11 Opolski M, Wilson I. Asthma and depression: a pragmatic review of the literature and recommendations for future research. Clin Pract Epidemiol Ment Health 2005; 1: 18.

12 Iessa N, Murray ML, Curran S, et al. Asthma and suicide-related adverse events: a review of observational studies. Eur Respir Rev 2011; 20: 287-292.

13 Moher D, Liberati A, Tetzlaff J, et al. Preferred reporting items for systematic reviews and meta-analyses: the PRISMA statement. Ann Intern Med 2009; 151: 264-269.

14 De Leo D, Burgis S, Bertolote JM, et al. Definitions of suicidal behaviour: lessons learned from the WHO/EURO Multicentre Study. Crisis 2006; 27: 4-15.

15 Pompili M, Forte A, Lester D, et al. Suicide risk in type 1 diabetes mellitus: a systematic review. J Psychosom Res 2014; 76: 352-360.

16 Druss B, Pincus H. Suicidal ideation and suicide attempts in general medical illnesses. Arch Intern Med 2000; 160: $1522-1526$.

17 Goodwin RD, Olfson M, Shea S, et al. Asthma and mental disorders in primary care. Gen Hosp Psychiatry 2003; 25: 479-483.

18 Goodwin RD, Marusic A. Asthma and suicidal ideation among youth in the community. Crisis 2004; 25: 99-102.

19 Goodwin RD, Eaton WW. Asthma, suicidal ideation, and suicide attempts: findings from the Baltimore epidemiologic catchment area follow-up. Am J Public Health 2005; 95: 717-722.

20 Bender BG. Depression symptoms and substance abuse in adolescents with asthma. Ann Allergy Asthma Immunol 2007; 99: 319-324.

21 Nomura Y, Brooks-Gunn J, Davey C, et al. The role of perinatal problems in risk of co-morbid psychiatric and medical disorders in adulthood. Psychol Med 2007; 37: 1323-1334.

22 Clarke DE, Goodwin RD, Messias EL, et al. Asthma and suicidal ideation with and without suicide attempts among adults in the United States: what is the role of cigarette smoking and mental disorders? Ann Allergy Asthma Immunol 2008; 100: 439-446.

23 Kuo CJ, Chen VCH, Lee WC, et al. Asthma and suicide mortality in young people: a 12-year follow-up study. Am J Psychiatry 2010; 167: 1092-1099.

24 Bae J, Park EY, Park SW. Modifying effect of suicidal ideation on the relationship between asthma and cigarette use behaviors among Korean adolescents. J Prev Med Public Health 2011; 44: 118-124.

25 Chan HL, Liu CY, Chau YL, et al. Prevalence and association of suicide ideation among Taiwanese elderly - a population-based cross-sectional study. Chang Gung Med J 2011; 34: 197-204.

26 Christiansen E, Stenager E. Risk for attempted suicide in children and youths after contact with somatic hospitals: a Danish register based nested case-control study. J Epidemiol Community Health 2012; 66: 247-253.

27 Chung SS, Joung KH. Risk factors related to suicidal ideation and attempted suicide: comparative study of Korean and American youth. J Sch Nurs 2012; 28: 448-458.

28 Goodwin RD, Demmer RT, Galea S, et al. Asthma and suicide behaviors: results from the Third National Health and Nutrition Examination Survey (NHANES III). J Psychiatr Res 2012; 46: 1002-1007.

29 Webb RT, Kontopantelis E, Doran T, et al. Suicide risk in primary care patients with major physical diseases: a case-control study. Arch Gen Psychiatry 2012; 69: 256-264.

30 Webb RT, Kontopantelis E, Doran T, et al. Risk of self-harm in physically ill patients in UK primary care. J Psychosom Res 2012; 73: 92-97.

31 Bandiera FC, Ramirez R, Arheart KL, et al. Asthma and suicidal ideation and behavior among Puerto Rican older children and adolescents. J Nerv Ment Dis 2013; 201: 587-591.

32 Bolton JM, Walld R, Chateau D, et al. Risk of suicide and suicide attempts associated with physical disorders: a population-based, balancing score-matched analysis. Psychol Med 2015; 45: 495-504.

33 Crump C, Sundquist K, Sundquist J, et al. Sociodemographic, psychiatric and somatic risk factors for suicide: a Swedish national cohort study. Psychol Med 2014; 44: 279-289.

34 Singhal A, Ross J, Seminog O, et al. Risk of self-harm and suicide in people with specific psychiatric and physical disorders: comparisons between disorders using English national record linkage. J R Soc Med 2014; 107: 194-204.

35 De Leo D, Scocco P, Marietta P, et al. Physical illness and parasuicide: evidence from the European Parasuicide Study Interview Schedule (EPSIS/WHO-EURO). Int J Psychiatry Med 1999; 29: 149-163.

36 De Leo D, Draper B, Snowdon J, et al. Suicides in older adults: a case-control psychological autopsy study in Australia. J Psychiatr Res 2013; 47: 980-988.

37 Hallfors DD, Waller MW, Ford CA, et al. Adolescent depression and suicide risk: association with sex and drug behavior. Am J Prev Med 2004; 27: 224-231.

38 Darlington TM, Pimentel R, Smith K, et al. Identifying rare variants for genetic risk through a combined pedigree and phenotype approach: application to suicide and asthma. Transl Psychiatry 2014; 4: e471.

39 Jick H, Hagberg KW, Egger P. Rate of suicide in patients taking montelukast. Pharmacotherapy 2009; 29: 165-166.

40 Philip G, Hustad C, Noonan G, et al. Reports of suicidality in clinical trials of montelukast. J Allergy Clin Immunol 2009; 124: 691-696.

41 Schumock GT, Stayner LT, Valuck RJ, et al. Risk of suicide attempt in asthmatic children and young adults prescribed leukotriene-modifying agents: a nested case-control study. J Allergy Clin Immunol 2012; 130: 368-375.

42 Schumock GT, Gibbons RD, Lee TA, et al. The association between leukotriene-modifying agents and spontaneously reported suicide. Drug Inf J 2012; 46: 99-106.

43 Favreau H, Bacon SL, Joseph M, et al. Association between asthma medications and suicidal ideation in adult asthmatics. Respir Med 2012; 106: 933-941. 